\title{
Growth-Associated Protein-43 Is Required for Commissural Axon Guidance in the Developing Vertebrate Nervous System
}

\author{
Yiping Shen, ${ }^{1,2}$ Shyamala Mani, ${ }^{2}$ Stacy L. Donovan, ${ }^{2}$ James E. Schwob, ${ }^{1}$ and Karina F. Meiri ${ }^{1}$ \\ ${ }^{1}$ Department of Anatomy and Cellular Biology, Tufts University School of Medicine, Boston, Massachusetts 02111, and \\ 2Programs in Cell and Molecular Biology and Neuroscience, State University of New York Upstate Medical University, \\ Syracuse, New York 13210
}

Growth-associated protein-43 (GAP-43) is a major growth cone protein whose phosphorylation by PKC in response to extracellular guidance cues can regulate F-actin behavior. Here we show that $100 \%$ of homozygote GAP-43 (-/-) mice failed to form the anterior commissure (AC), hippocampal commissure $(\mathrm{HC})$, and corpus callosum (CC) in vivo. Instead, although midline fusion was normal, selective fasciculation between commissural axons was inhibited, and TAG-1-labeled axons tangled bilaterally into Probst's bundles. Moreover, their growth cones had significantly smaller lamellas and reduced levels of F-actin in vitro. Likewise, $100 \%$ of GAP-43 (+/-) mice with one disrupted allele also showed defects in $\mathrm{HC}$ and $\mathrm{CC}$, whereas the AC was unaffected. Individual GAP-43 (+/-) mice could be assigned to two groups based on the amount that PKC phosphorylation of GAP-43 was reduced in neocortical neurons. In mice with $\sim 1 \%$ phosphorylation, the $\mathrm{HC}$ and $\mathrm{CC}$ were absent, whereas in mice with $\sim 10 \%$ phosphorylation, the $\mathrm{HC}$ and CC were smaller. Both results suggest that PKC-mediated signaling in commissural axons may be defective. However, although Probst's bundles formed consistently at the location of the glial wedge, both GAP-43 (-/-) and GAP-43 (+/+) cortical axons were still repulsed by Slit-2 in vitro, precluding failure of this deflective signal from the glial wedge as the source of the phenotype. Nonetheless, the data show that a functional threshold of GAP-43 is required for commissure formation and suggests that failure to regulate F-actin in commissural growth cones may be related to inhibited PKC phosphorylation of GAP-43.

Key words: anterior commissure; hippocampal commissure; corpus callosum; GAP-43; F-actin; PKC; Slit-2
Communication between the telencephalic hemispheres occurs through three major commissures: the corpus callosum (CC), the hippocampal commissure (HC), and the anterior commissure (AC) (Abbie, 1940). Mutational and genetic analyses have identified several environmental cues that guide axons through the commissures during development (Tear, 1999) and have also shown a crucial requirement for actin regulation. Thus, genetic deletion of F-actin binding proteins such as myrisotylated alanine-rich C kinase substrate (MARCK) (Stumpo et al., 1995), MacMARCKs (Chen et al., 1996), $\operatorname{ankyrin}_{\mathrm{B}}$ (Scotland et al., 1998), Mena (Lanier et al., 1999), and p190RhoGAP (Brouns et al., 2000) all prevent commissure formation. However, in these instances, defects in midline fusion may also contribute to the phenotype. Thus, how guidance cue receptors are coupled to cytoskeletal effectors within commissural growth cones during midline crossing remains little understood (Mueller, 1999).

Growth-associated protein-43 (GAP-43) is a single copy gene that is a major neuronal substrate of protein kinase $\mathrm{C}$ (PKC) and, like Mena, MARCKs, MacMARCKs, and p190rhoGAP, modulates F-actin in growth cones (He et al., 1997; Oestreicher et al.,

Received Aug. 15, 2001; revised Oct. 1, 2001; accepted Oct. 19, 2001

This work was supported by National Institutes of Health (NIH) Grant NS33118. S.L.D. was supported by NIH Grants NS31829 and IBN-9724102. We thank Dr. Y. Rao for Slit-2-transfected cells, Dr. D. Wahlsten for discussions, and Dr. T. J. Diefenbach for help with microscopy of the cultures.

Correspondence should be addressed to Dr. Karina Meiri, Department of Anatomy and Cellular Biology, Tufts University School of Medicine, 136 Harrison Avenue, Boston, MA 02111. E-mail: karina.meiri@tufts.edu.

S. Mani's present address: National Brain Research Centre, International Center for Genetic Engineering and Biotechnology Campus, Aruna Asaf Ali Marg, New Delhi 110067, India.

Copyright $\odot 2001$ Society for Neuroscience $0270-6474 / 01 / 220001-09 \$ 15.00 / 0$
1997). Like MARCKs also, regulation of F-actin depends on its phosphorylation status: PKC-phosphorylated GAP-43 is spatially segregated to motile and advancing lamellas and filopodia (Dent and Meiri, 1998) and stabilizes actin filaments in vitro by removing them from the polymerization-depolymerization cycle $(\mathrm{He}$ et al., 1997). In contrast, unphosphorylated GAP-43 is enriched in retracting or collapsing lamellas (Dent and Meiri, 1992) and inhibits F-actin polymerization in vitro (He et al., 1997). Phosphorylation of GAP-43 by PKC in growth cones can be stimulated by Ig superfamily cell adhesion molecules (IgSF-CAMs), such as L1, that have been implicated in commissural axon guidance (Kamiguchi et al., 1998; Demyanenko et al., 1999). Neurites require GAP-43 to respond to IgSF-CAM-mediated signals in vitro (Meiri et al., 1998).

In mice, failure to express GAP-43 gives rise to a severe in vivo phenotype: $>95 \%$ of GAP-43 $(-/-)$ mice die perinatally, with abnormalities of axonal pathfinding reflected in failure to form topographic maps in somatosensory, visual, and auditory cortices (Maier et al., 1999). Axon guidance at the optic chiasm is also disrupted (Strittmatter et al., 1995; Kruger et al., 1998; Sretavan and Kruger 1998). Here we investigated telencephalic commissure formation in GAP-43-deficient mice that were generated from targeted CJ7 embryonic stem cells in isogenic 129S3/imJ mice (genetic designation $+{ }^{\text {Mgf-SIJ }}$ JAX stock number 002448, Bar Harbor, ME) and backcrossed for 8-12 generations with C57BL/6N. Homozygote GAP-43 (-/-) mice failed to form the $\mathrm{AC}, \mathrm{HC}$, and CC. Significantly midline fusion was normal. Moreover, growth cones from commissural axons had smaller lamellas and reduced F-actin immunoreactivity. None of the GAP-43 $(+/+)$ mice from either genetic background (129S3/imJ or 
C57BL/6N) showed any commissural defects, precluding congenital abnormalities as the source of the phenotype. Furthermore, the severity of commissural dysgenesis in individual GAP-43 $(+/-)$ mice was directly proportional to the amount that phosphorylation of GAP-43 was reduced. The results suggest that the functional threshold of GAP-43 requires its phosphorylation by $\mathrm{PKC}$ in commissural growth cones.

\section{MATERIALS AND METHODS}

Histology and immunocytochemistry. Anesthesia by halothane inhalation was followed by perfusion with PBS, $\mathrm{pH} 7.4$, followed by Bouin's fixative. Brains were post-fixed in Bouin's, embedded in paraffin, and sectioned at $14 \mu \mathrm{m}$. Staining used Nissl and GAP-43 immunohistochemistry used $7 \mathrm{~B} 10$ [the pan-GAP-43 monoclonal antibody (mAb)] or $2 \mathrm{G} 12$ (the phospho-specific mAb) (Dent and Meiri, 1998). For TAG-1 immunohistochemistry with 4D7 (Developmental Studies Hybridoma Bank, University of Iowa, Iowa City, IA), brains were fixed in $4 \%$ paraformaldehyde (PFA) and cryosectioned at $14 \mu \mathrm{m}$. Sections were blocked in PBS containing $10 \%$ serum according to the 20 antibodies and permeabilized with $0.02 \%$ digitonin. The 20 FITC- and Texas Red-conjugated antibodies were from Vector Laboratories (Burlingame, CA).

Dye tracing. Brains from postnatal day 0 (P0) animals fixed in $4 \%$ PFA were double dye labeled with a single crystal of Fast DiA [4-(4dilinoleyamino)stryryl)- $N$-methyl-pyridinium iodide, 4-chlorobenzenesulfonate] and Fast DiI (1,1'-dilinoleyl-3, 3,3',3'-tetramethyl-indocarbocyanine 4-cholorobenzenesulfonate] (Molecular Probes, Eugene, OR) implanted into the cortical layer of frontal cortex and the occipital cortex, respectively (Ozaki and Wahlsten, 1992). Labeled brains were incubated at $37^{\circ} \mathrm{C}$ for $30 \mathrm{~d}$ and sectioned sagittally at $50 \mu \mathrm{m}$.

Dissociated cultures. Fetuses were dissected from timed pregnant GAP-43 (+/-) females [embryonic day 15.5 (E15.5); noon of day on which plug is found is E0.5] and kept in cold sterile Gray's solution while a modified multiplex PCR was performed on tail samples (Maier et al., 1999). After genotyping, neocortices from identified $(-/-)$ and $(+/+)$ mice were cut into $3 \times 4 \mathrm{~mm}$ pieces using a McIllwain tissue chopper, rinsed in $\mathrm{Ca}^{2+}$ and $\mathrm{Mg}^{2+}$-free HBSS, and digested with trypsin EDTA. Serum-containing culture medium (DMEM plus $10 \%$ horse serum plus $0.1 \%$ penicillin-streptomycin) was added, and cells were dispersed by trituration. Dissociated cells were recovered from the $400 \mathrm{rpm}$ pellet, resuspended in culture medium, and plated onto poly-D-lysine-coated eight-well Lab-Tek (Naperville, IL) plates at low density (800-1000 cells per well). Cultures were grown in $5 \% \mathrm{CO}_{2}$ at $37^{\circ} \mathrm{C}$. After $24 \mathrm{hr}$ in vitro, dissociated cortical neurons were fixed with prewarmed $4 \%$ paraformaldehyde in PBS as described previously (Dent and Meiri, 1998) and then double labeled with anti-TAG 1 antibody, followed by biotin-labeled secondary antibody and streptavidin-labeled FITC (Vector Laboratories). Rhodamine phalloidin (Molecular Probes) was applied for $40 \mathrm{~min}$ before cells were coverslipped with Vectashield mounting medium (Vector Laboratories). Quantitation of area and documentation of immunoreactivity with TAG-1 and phalloidin was done blindly on growth cones selected as the microscope stage was moved in the same random pattern around each well.

Collagen gel cocultures. E15.5 fetuses were dissected and genotyped as before. Neocortex was separated from cortex and the area of the neocortex previously described as giving rise to callosal axons (Ozaki and Wahlsten, 1998), cut into $200 \mu \mathrm{m}^{3}$ cubes with a McIllwain tissue chopper, and kept in cold L-15 medium with $0.6 \%$ glucose until embedding in collagen. HEK 293 cells stably transfected with Slit-2 or vector alone (a generous gift of Dr Y. Rao, Washington University, St. Louis, MO) were premixed with collagen gel [900 $\mu$ l of Vitrogen 100 (Cohesion, Palo Alto, CA), $100 \mu \mathrm{l}$ of 100× DMEM (Life Technologies, Gaithersburg, MD), and $23 \mu \mathrm{l}$ of $1 \mathrm{M} \mathrm{NaHCO}_{3}$ ]. Approximately $5-6 \mu \mathrm{l}$ of gel was dotted onto eight-well Lab-Tek slides, gelled in a $37^{\circ} \mathrm{C}$ incubator for $15-20 \mathrm{~min}$, and then overlaid with $100 \mu \mathrm{l}$ of collagen gel. Tissue pieces were placed in the collagen gel at a distance of $100-300 \mu \mathrm{m}$ from the cell-gel mix. After the collagen gelled, $500 \mu \mathrm{l}$ of culture medium consisting of DMEM with GlutaMAX, $10 \%$ horse serum, and $0.1 \%$ penicillin-streptomycin was added to each well. Explants were cultured for $24 \mathrm{hr}$ in a humidified $\mathrm{CO}_{2}$ incubator, and live cultures were photographed using differential interference contrast optics. Cultures were fixed after $48 \mathrm{hr}$. To quantitate the response of the explants, explants from the $24 \mathrm{hr}$ photographs were bisected parallel to the orientation of the transfected cells, and neurites were counted. An attractive response was defined as $>70 \%$ of neurites in the hemisphere adjacent to the transfected cells, whereas a repulsive response was defined as $>70 \%$ of the neurites in the hemisphere distant from the transfected cells. A response was scored as neutral when there was no difference in the distribution of neurites between the two hemispheres. Explants that did not send out neurites were not included.

Microscopy. Laser-scanning confocal microscopy of both immunostained and dye-labeled sections used an MRC 1024 microscope (BioRad, Hercules, CA) equipped with a single krypton-argon laser and T1 and T2A filters using identical parameters for direct comparison between samples. Dissociated cortical neurons were viewed under FITC and rhodamine optics at $60 \times$ magnification using a Nikon (Tokyo, Japan) Diaphot 200 microscope and ND4 and ND2 filters. Cultures were photographed with a Hamamatsu (Hamamatsu City, Japan) 4742-95 CCD camera under identical conditions, and images were saved as TIFF files using Openlab (Improvision Inc., Lexington, MA) software. All postphotography manipulations of images were identical. Area measurements and densitometry F-actin labeling of TAG-1 immunoreactive growth cones with rhodaminated phalloidin used IP Lab (Scanalytics Inc., Fairfax, VA).

Western blot analysis. Forebrains from P0 mice were rapidly dissected, homogenized in $10 \mathrm{~mm}$ Tris, $2 \mathrm{~mm}$ DTT, $1 \mathrm{~mm}$ PMSF, and 5 mM EDTA, $\mathrm{pH} 7.4$, at $4^{\circ} \mathrm{C}$, and centrifuged at $100,000 \times g$ for $30 \mathrm{~min}$. Microsomal proteins were separated by $10 \%$ PAGE, transferred to polyvinylidene difluoride membrane, and incubated with either 7 B10 or 2 G12. Specific immunoreactivity was detected with ${ }^{125}$ I-labeled anti-mouse IgG (specific activity $18 \mu \mathrm{Ci} / \mu \mathrm{g}$ ) and quantitated by PhosphorImager analysis (Molecular Dynamics, Sunnyvale, CA) using Imagequant software (He et al., 1997).

\section{RESULTS}

\section{GAP-43 (-/-) mice fail to form telencephalic commissures}

The telencephalic commissures have distinct roles and developmental histories: the largest is the $\mathrm{CC}$, which interconnects the neocortex; the $\mathrm{HC}$ interconnects the archicortex, principally the hippocampus; and the AC interconnects paleocortex, components of the amygdala, interhippocampal gyrus, and temporal neocortex (Fig. $1 a, c, e)$. At P0, no axon bundles crossing the midline could be detected in Nissl-stained, midsagittal sections from GAP-43 $(-/-)$ brains (Fig. 1b). Instead, $\mathrm{CC}$ and $\mathrm{HC}$ axons formed neuroma-like whorls (Probst's bundles) on either side of the midline, which could be detected in either Nissl-stained horizontal sections (Fig. 1d) or anti-TAG-1 immunolabeled coronal sections (Fig. 1f). The phenotype resembles human type 1 callosal agenesis, which is considered to be an axon guidance defect (Kamiguchi et al., 1998). The diverse origins of the AC give rise to more complex behavior (Velut et al., 1998). The anterior branch, which is derived from the anterior olfactory nucleus and anterior piriform cortex, was immunolabeled with TAG-1, like the $\mathrm{CC}$ and $\mathrm{HC}$, and likewise formed Probst's bundles (Fig. 2f). In contrast, the posterior branch, which is derived from piriform and temporal cortices, was not immunolabeled with TAG-1 (Fig. 2d) and did not form Probst's bundles, instead defasciculating and descending posteroventrally (Fig. $2 a$ ).

Failure to express GAP-43 prevents formation of the telencephalic commissures completely. In GAP-43 $(+/+)$ mice between $\mathrm{P} 7$ and P21, the CC increased in area by 1.74 -fold, the HC by 2.8-fold, and the AC by 1.5-fold. In contrast, no axons crossed the midline in any of the GAP-43 (-/-) mice up to P21. Quantitation used three mice at each time point.

\section{GAP-43 (-/-) commissural growth cones have reduced lamellal area and levels of F-actin in vitro}

Total absence of GAP-43 had two effects on TAG-1-labeled neocortical (presumed callosal) growth cones, which are illustrated in Figure 3. First, although GAP-43 (-/-) TAG-1-labeled cultures extended neurites normally in dissociated cultures, the 

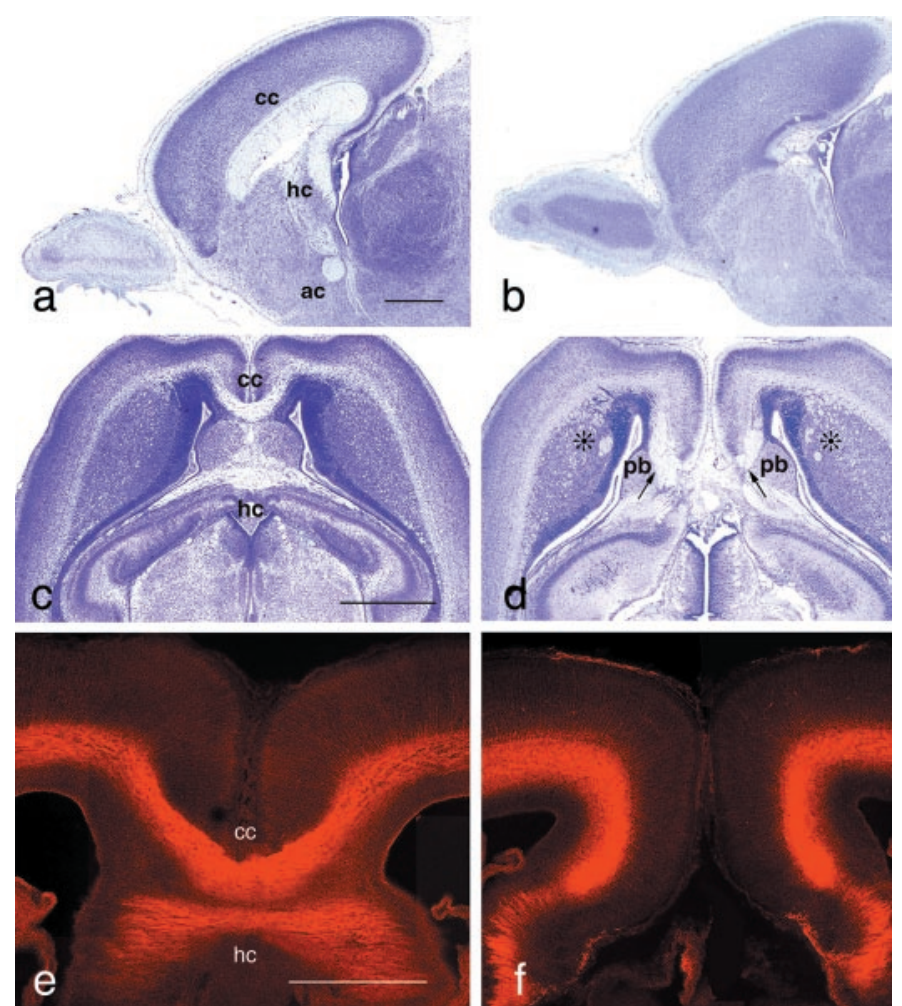

Figure 1. $a, b$, Nissl-stained parasagittal sections at P0. $a$, GAP-43 $(+/+)$ showing corpus callosum $(c c)$, hippocampal commissure $(h c)$, and anterior commissure $(a c)$. $b$, GAP-43 (-l-) showing no commissures. $c, d$, Nissl-stained horizontal sections at P0. $c$, GAP-43 $(+/+)$ showing $\mathrm{CC}$ and $\mathrm{HC} . d$, GAP-43 (-/-) showing that midline commissural axons tangle into Probst's bundles $(p b)$. Asterisks indicate inappropriate fasciculation of axons in the corpus striatum. $e, f$, Coronal sections at P0 labeled with the anti-TAG1 mAb 4D7, followed by TRITC-labeled secondary antibody. $e$, GAP-43 (+/+) showing CC and HC. $f$, GAP-43 (-l-) showing no midline crossing (Probst's bundles themselves are located more anteriorly than this section illustrates). No callosal or hippocampal commissures ever formed in GAP-43 $(-/-)$ mice $(n=12)$. Scale bars, $500 \mu \mathrm{m}$.

surface areas of their growth cones were reduced from $60.36 \pm$ $4.76 \mu \mathrm{m}^{2}$ [SEM; $n=54$ GAP-43 $(+/+)$ growth cones from 10 random fields from four independent cultures] to $41.06 \pm 6.6 \mu \mathrm{m}^{2}$ [SEM; $n=56$ GAP-43 (-/-) growth cones from 10 random fields from four cultures]. This reduction of $32 \%$ was statistically significant ( $p<0.001$; two-tailed $t$ test). Second, levels of F-actin were reduced from an average pixel intensity of rhodaminated phalloidin of $136.5 \pm 9.4$ [SEM; $n=45$ GAP-43 $(+/+)$ growth cones from 10 random fields from four independent cultures] to $64.8 \pm 7.5$ [SEM; $n=27$ GAP-43 (-/-) growth cones from eight random fields from four independent cultures]. This reduction of $57 \%$ was also statistically significant ( $p<0.001$; two-tailed $t$ test). In contrast, no consistent differences were seen in the pixel intensities of rhodamine phalloidin between TAG-1-labeled GAP-43 $(+/+)$ or $(-/-)$ cell bodies. Hence, GAP-43 is required to maintain F-actin levels in dissociated callosal growth cones in culture.

\section{GAP-43 (-/-) axons respond normally to Slit-2}

Axon guidance across the corpus callosum requires that axons are deflected toward the midline. One source of repulsive cues is the glial wedge, located bilaterally to the midline, which secretes
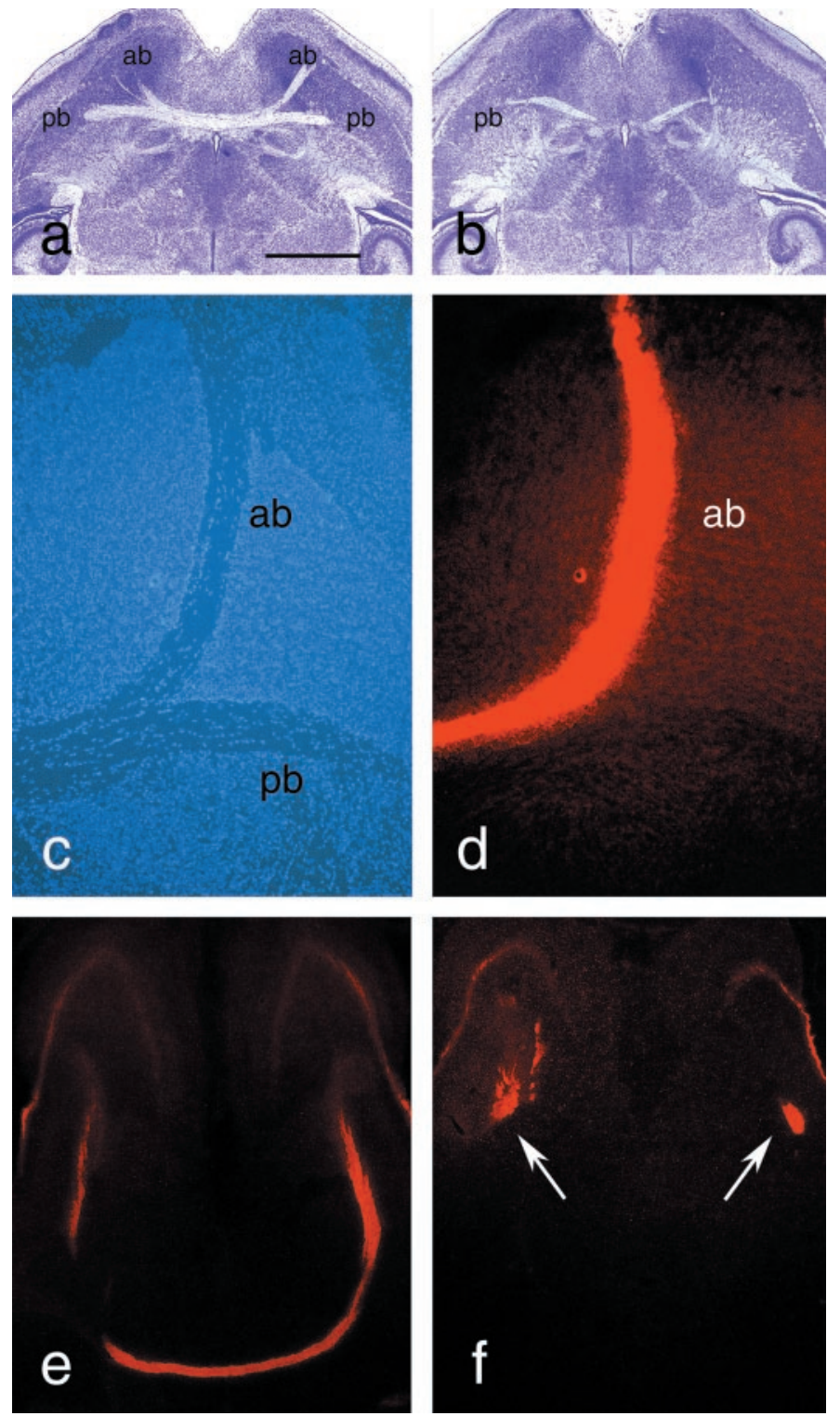

Figure 2. $a, b$, Nissl-stained coronal sections at P0. $a$, GAP-43 $(+/+)$ showing both anterior $(a b)$ and posterior $(p b)$ branches of the anterior commissure. $b$, GAP-43 $(-/-)$ showing only posterior branches. Neither branch crossed the midline. $c, f$, Coronal sections at P0. $c$, GAP-43 $(+/+)$ visualized by differential interference contrast showing the anterior and posterior branches. $d$, Same section after TAG-1 immunohistochemistry to show that only the anterior branch is labeled with TAG-1. $e$, GAP-43 $(+/+)$ after TAG-1 immunohistochemistry showing TAG-1-labeled (anterior branch) axons crossing the midline. $f$, GAP-43 (-/-) after TAG-1 immunohistochemistry showing TAG-1-labeled (anterior branch) axons formed Probst's bundles (arrows). Scale bar: $a, b, 500 \mu \mathrm{m} ; c, d, 100 \mu \mathrm{m} ; e$, $f, 250 \mu \mathrm{m}$.

Slit-2 (Shu and Richards, 2001). In GAP-43 (+/+) mice, the glial wedge was highly immunoreactive with GFAP antibody, visualized with tetramethylrhodamine isothiocyanate (TRITC) labeled secondary antibody (Fig. $4 a$ ). In contrast, although the glial wedge was present in GAP-43 (-/-) mice, it was very poorly immunoreactive with GFAP and instead labeled with anti-RC1 antibody, a marker of immature glia (Fig. 4b,c, green, arrows). GAP-43 $(-/-)$ axons that fail to cross the midline consistently formed Probst's bundles in the area of the glial wedge, partially obscuring 

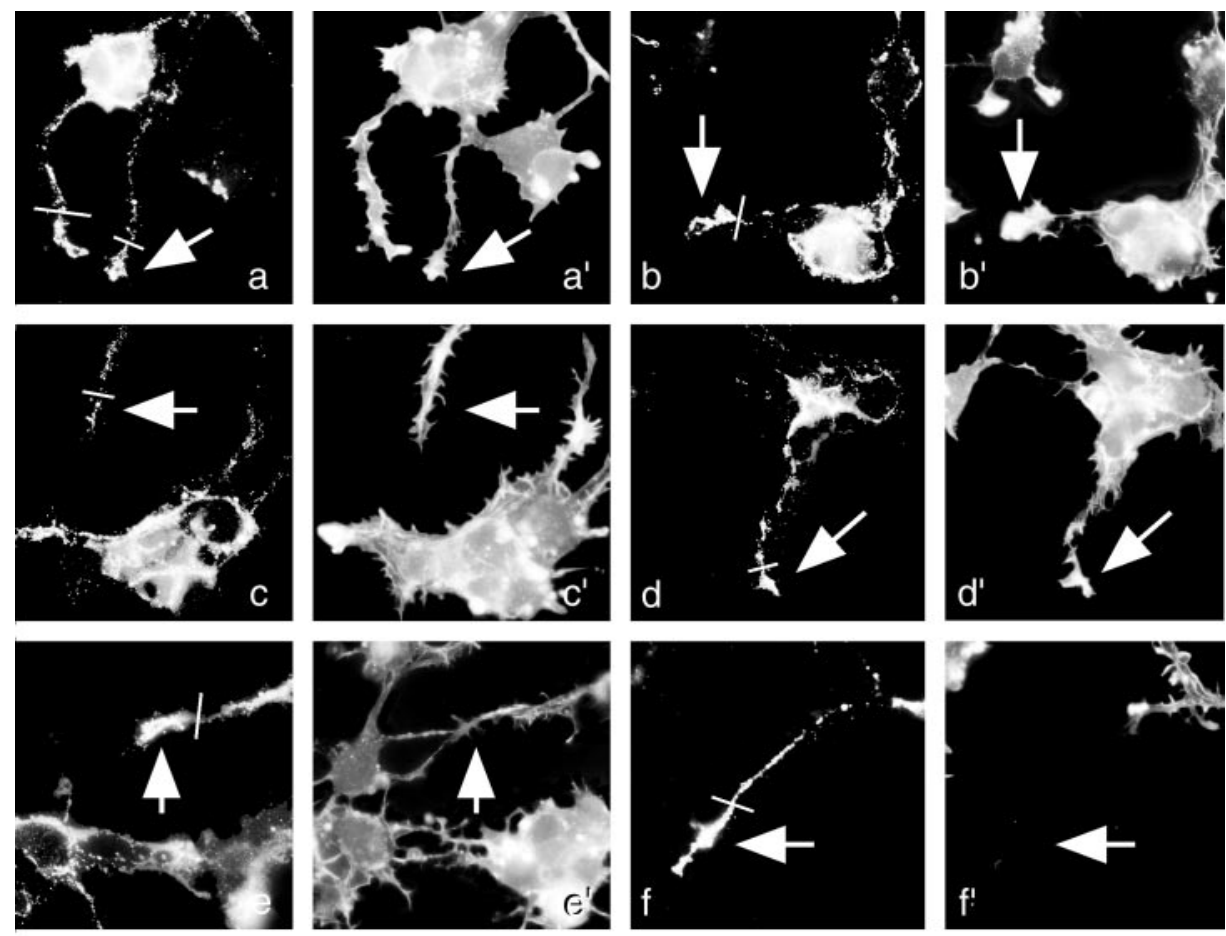

Figure 3. Growth cones from dissociated cortical cultures from GAP-43 $(+/+)(a-d)$ or GAP-43 (-/-) $(e-h)$ mice double labeled with TAG-1 $(a-h)$ and rhodamine phalloidin $\left(a^{\prime}-h^{\prime}\right)$ after $24 \mathrm{hr}$ in vitro. Arrows indicate the growth cone used for measuring both lamellal area and pixel intensity of rhodamine phalloidin labeling with IP Lab (Scanalytics Inc.). Lines bisecting neurites indicate limit of growth cones used for measurement. Scale bar, $100 \mu \mathrm{m}$.
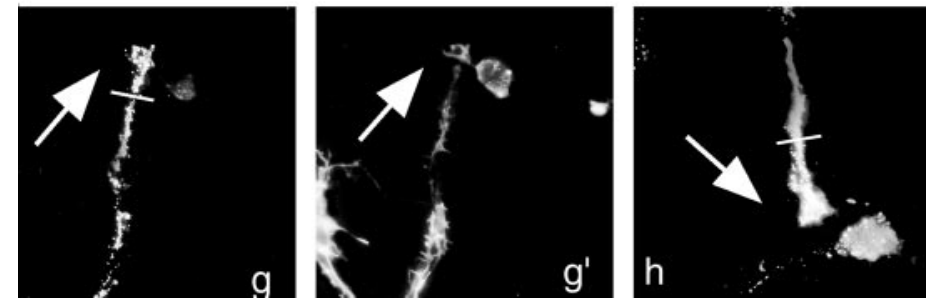

it at this level (Fig. 4b,c). In contrast, glia within the Probst's bundles were immunoreactive with GFAP. The results raise the question of whether the Probst's bundles arise at this location because callosal axons fail to respond to Slit-2-mediated deflective signals supplied by the glial wedge. Indeed, explants of E15.5 GAP-43 $(+/+)$ neocortex were strongly repulsed by Slit-2 when they were cocultured with transfected cells in collagen gels in vitro ( $n=14$ explants) (Fig. 4d, black bars). However, GAP-43 (-/-) explants were also strongly repulsed by Slit-2 under similar conditions ( $n=14$ explants) (Fig. $4 d$, white bars). The results therefore suggest that, although GAP-43 (-/-) callosal axons consistently form Probst's bundles in the vicinity of the glial wedge, with consequent failure to cross the midline, this defect cannot be attributed to failure of the GAP-43 (-/-) axons to respond to Slit-2-mediated signals.

\section{Absence of GAP-43 affects selective fasciculation rather than axon elongation}

Implanting Fast DiI and Fast DiA into frontal cortex and occipital cortex, respectively, demonstrated that callosal axons at the midline of GAP-43 $(+/+)$ mice show rough topographic organization in both the anteroposterior and dorsoventral axes (Fig. 5a), consistent with selective fasciculation between commissural axons that derive from neighboring areas, as has been reported previously (Ozaki and Wahlsten, 1992). In contrast, no labeled fibers reached the midline in GAP-43 $(-/-)$ mice as expected (Fig. 5b). Similarly, when parasagittal sections were taken at the distance from the midline at which Probst's bundles are found in the $(-/-)$ mice, topographic orientation was maintained in the GAP-43 $(+/+)$ sections. In contrast a similar section through GAP-43 (-/-) Probst's bundles revealed mixing of dye-labeled axons and significant misrouting: axons exited the bundles in trajectories that invaded anterior territories inappropriately (Fig. 5d). Thus, GAP-43 is also required for selective fasciculation to maintain topographic organization of commissural axons.

\section{Commissural agenesis is not attributable to a congenital abnormality in the GAP-43 (-/-) mice}

Callosal dysgenesis has been described in several of the inbred 129 substrains often used to make knock-out mice, although not in the129S3/imJ substrain from which our mice were derived (Livy and Wahlsten, 1991; Magara et al., 1999; Wahlsten et al., 1999). The congenital abnormalities differ from the GAP-43 phenotype: the HC and the AC are normal in affected adults (Livy and Wahlsten, 1991), and the trait is recessively inherited (see below). To conclusively verify that the phenotype we described above reflects genetic deletion of GAP-43 rather than congenital abnormalities in the $129 \mathrm{~S} 3 / \mathrm{imJ}$ substrain that persists despite backcrossing, we repeated the experiments in the founder 129S3/ imJ colony. None of the GAP-43 $(+/+)$ mice $(n>25)$ showed any abnormalities in telencephalic commissures. Thus, the commissural phenotype described here cannot be attributed to congenital defects in the 129S3/imJ substrain. 

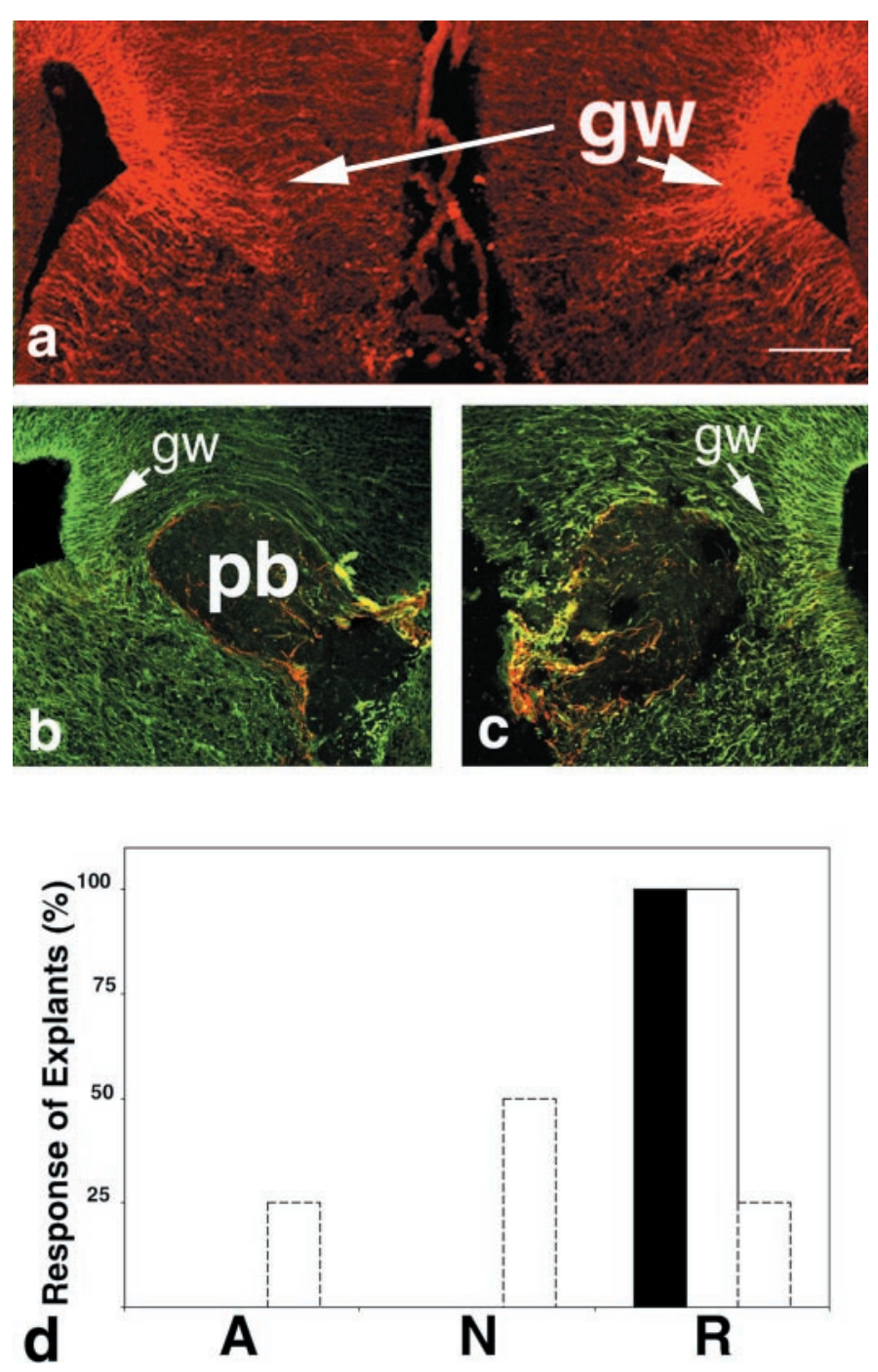

Figure 4. $a$, Coronal confocal section of E17.5 GAP-43 (+/+) cortex labeled with GFAP $\mathrm{mAb}$, followed by TRITC showing bilateral localization of the glial wedge ( $g w$; arrows), which is highly immunoreactive with GFAP. $b, c$, Similar sections of GAP-43 (-/-) cortex double labeled with GFAP, followed by TRITC and RC1 followed by FITC. Note that the glial wedge ( $g w$; arrows) is detected by RC1 immunoreactivity but is very poorly immunoreactive with GFAP. The Probst's bundles $(p b)$ are consistently localized in the vicinity of the glial wedge and are immunoreactive with GFAP. Scale bar, $125 \mu \mathrm{m}$. $d$, Quantitation of the responses of each explant culture to Slit-2-expressing HEK 293 cells suspended in a collagen gel capsule. A response was defined as attractive $(A)$ when $>70 \%$ of the total neurites grew in the hemisphere adjacent to the cell-gel capsule, whereas a response was defined as repulsive $(R)$ when $>70 \%$ of the total neurites grew in the hemisphere distant from the cell-gel capsule. A response was defined as neutral $(N)$ when neurites in neither hemisphere were $>70 \%$ of total. Black bars represent GAP-43 $(+/+)$ cultures $(n=14)$, and white bars represent GAP-43 $(-/-)$ cultures $(n=$ 12). Dashed bars represent GAP-43 $(+/+)$ cultures $(n=4)$ cocultured with HEK 293 cells expressing vector alone as control.

\section{Commissure formation is also defective in heterozygote GAP-43 (+/-) mice}

The telencephalic commissures were also abnormal in the GAP-43 (+/-) mice. Both CC and HC were totally absent in 39\% of mice (16 of 41) examined at P0, P7, and P21 (Fig. 6c) and was reduced in the remainder (25of 41) (Fig. 6a,b). The reduction in the cross-sectional area of the $\mathrm{HC}-\mathrm{CC}$ at the midline was significant at each time point ( $p<0.01$; two-tailed $t$ test) (Fig. $6 d$ ). The rate of increase was also reduced, suggesting that $\mathrm{HC}$ and $\mathrm{CC}$ axons grow more slowly or that they were misrouted (Fig. $6 d$ ). However, DiI labeling of CC and HC axons showed no evidence that they were rerouted through the AC (results not shown). In contrast, the midline cross-sectional area of the $\mathrm{AC}$ was not affected in the GAP $(+/-)$ mice.

\section{The severity of the callosal phenotype in GAP-43 (+/-) mice correlates with amount of PKC phosphorylated GAP-43}

Both levels of GAP-43 expression and its phosphorylation by PKC were significantly reduced in the GAP-43 (+/ -$)$ mice, and, moreover, there was a strong correlation between the reduction and severity of the commissural phenotype. Levels of GAP-43, detected with the pan-GAP-43 mAb 7 B10 (data not shown), or PKC-phosphorylated GAP-43 detected with the phospho-specific mAb 2 G12 (Fig. 7), were lower in most areas of the forebrain and brainstem (Fig. 7b,c). Phosphorylated GAP-43 was lowest when the $\mathrm{CC}$ and $\mathrm{HC}$ were absent (Fig. 7c). In contrast, expression and phosphorylation of GAP-43 in the AC appeared normal, as did the AC itself (see below). We quantitated GAP-43 expression and phosphorylation in anterior cortex of two litters of mice by Western blotting and used ${ }^{125}$ I-labeled secondary antibody to detect specific immunoreactivity, as we had done previously ( $\mathrm{He}$ et al., 1997). In addition, we measured the midline cross-sectional area of the $\mathrm{CC}$ and the $\mathrm{AC}$ in the same mice (Fig. $7 d$ ). The GAP-43 (+/-) mice expressed only $27.3 \pm 3.5 \%$ of $(+/+)$ levels of GAP-43 protein. However, they could be assigned to two distinct groups on the basis of the levels of phosphorylation that were independent of the litter from which they were derived. In the first group, phosphorylated GAP-43 was between 1.3 and $1.8 \%$ of wild type $(n=4)$; these animals were all acallosal. In the second group, phosphorylated GAP-43 was between 4.4 and $10.6 \%$ of wild type $(n=6)$; here the $\mathrm{CC}$ was between 19.9 and $63.7 \%$ of normal. The area of the AC averaged $93.7 \pm 0.25 \%$ of $(+/-)(n=10$ from both litters). The results show that a functional threshold of GAP-43 is required for $\mathrm{CC}$ formation. The threshold strictly parallels the amount of phosphorylated GAP-43 in anterior cortex, the source of callosal axons.

\section{DISCUSSION}

Our results here show that GAP-43, a protein whose phosphorylation in response to extracellular signals can regulate actin dynamics in growth cones (Dent and Meiri 1992, 1998; He and Meiri, 1997; Rosner and Vacun, 1999), is required for formation of the major interhemispheric projection pathways in the telencephalon. Both homozygotes and heterozygotes are affected, and the phenotype is the most severe thus far described for telencephalic commissure formation. Together with our previous results showing that GAP-43 (-/-) mice also have profound defects in thalamocortical ingrowth resulting in failure to form topographic maps in the cortex (Maier et al., 1999), they pinpoint GAP-43 as a major contributor to cortical assembly in vertebrates.

The commissural phenotype is independent of the genetic background of the mice and reflects the targeted deletion at the GAP-43 locus: congenital callosal dysgenesis occurs in several inbred mouse strains, including some 129 substrains, namely 129/Ola,129P3/J, 129/ReJ, and 129sv/ev (Livy and Wahlsten, 1991; Livy et al., 1997; Magara et al., 1999; Wahlsten et al., 1999). It has never been described in the 129S3/svImJ substrain, from which the CJ7 embryonic stem cells were derived. Nor have we encountered it in $>25$ wild-type $129 \mathrm{~S} 3 /$ svImJ mice or in $>75$ 

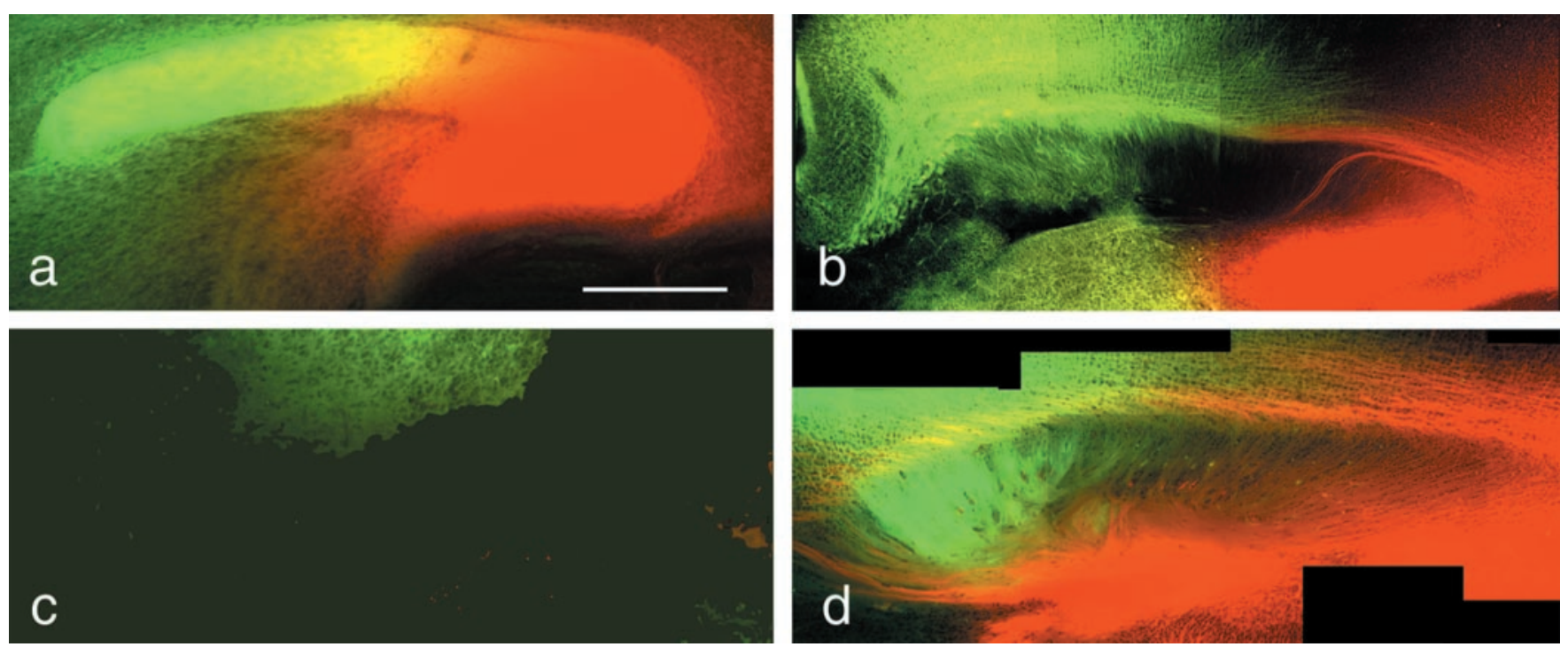

Figure 5. Parasaggital sections of GAP-43 $(+/+)(a, b)$ and GAP-43 $(-/-)(c, d)$ mice that have been labeled in frontal cortex with a crystal of DiI ( green) and in occipital cortex with a crystal of DiA (red). $a, c$, Sections at the midline showing appropriate topographic organization of GAP-43 (+/+) callosal axons $(a)$ but no GAP-43 (-/-) axons crossing the midline $(c) . b, d$, Sections taken at the distance from the midline in which Probst's bundles are found in the $(-/-)$ mice $(d)$. Again, topographic organization of label is seen in the GAP-43 $(+/+)$ section $(b)$ but abnormal mixing and projection of axons in the GAP-43 (-/-) section $(d)$. Scale bar, $500 \mu \mathrm{m}$.

wild-type 129S3/svImJ//C57BL/6N 8-12 generation backcrosses, in which $99.9 \%$ of the genome derives from the C57BL/6N background and in which the mutation is maintained. Current models suggest that at least three separate loci are involved in congenital callosal dysgenesis (Livy and Wahlsten, 1991; Magara et al., 1999; Wahlsten et al., 1999) and that at least four of the recessive alleles (from two of the putative three loci) are required for a phenotype to become evident (Livy and Wahlsten, 1991). In addition, the action of genetic modifiers causing phenotypic variation among the isogenic sibs has been seen in other mouse strains (Bulman-Fleming and Wahlsten, 1991). In contrast, the GAP-43 phenotype requires only one affected allele. Moreover, the penetrance is $100 \%$ in both homozygotes and heterozygotes, significantly more than that seen in the congenitally affected mice. Thus, the abnormalities described here are attributable to disruption of the GAP-43 gene. However, we cannot rule out, and indeed it seems highly likely, that genetic modifiers contribute to the reduction of GAP-43 levels in the heterozygotes.

Partial depletion of GAP-43 in growth cones with antibodies or oligonucleotides in vitro resulted in unstable lamellas and a reduction of F-actin (Aigner and Caroni, 1993; Frey et al., 2000), suggesting that a functional threshold of GAP-43 is required for regulation of F-actin growth cone function. Our results, showing that both lamellal area and F-actin levels were also significantly reduced in TAG-1-labeled GAP-43 (-/-) commissural growth cones, confirm those data. Moreover, the GAP-43 heterozygotes strongly suggest that PKC-phosphorylated GAP-43 is a major functionally relevant form in vivo. Thus, the $\mathrm{HC}$ and $\mathrm{CC}$ mice were absent in mice with only $1 \%$ of normal phosphorylation and significantly smaller in mice with only $10 \%$ of normal phosphorylation. Because the phosphorylation status of GAP-43 determines whether it will stabilize F-actin (phosphorylated GAP-43) or prevent F-actin polymerizing (unphosphorylated GAP-43; see introductory remarks) (He et al., 1997; Rosner and Vacun, 1999), we hypothesize that the effects on phosphorylation and F-actin are causally related. However, we cannot rule out that unphosphorylated GAP-43 also has indirect effects on F-actin via phos- phatidyl inositol bis phosphate, which also contribute to the phenotype (Laux et al., 2000; Tejero-Diez et al., 2000).

The close correlation between reduced levels of PKCphosphorylated GAP-43 and the severity of the phenotype in GAP-43 (+/-) mice further implicates PKC in the regulation of commissural axon guidance. Direct activation of PKC in growth cones concurrently increases elaboration of motile lamellas and levels of phosphorylated GAP-43 within them (Rosner and Vacun, 1999). These effects on growth cone dynamics are prevented by inhibitors of PKC and F-actin polymerization (Rosner and Vacun, 1999), suggesting that regulation of GAP-43 by PKC phosphorylation may modulate F-actin behavior in commissure growth cones in vivo, as it does in vitro (He et al., 1997).

Like GAP-43, Mena, MARCKs, and p190RhoGAP interact with F-actin and are enriched in growth cones. However, the commissural defects seen when they are genetically deleted have been attributed, in part, to inhibition of neural tube closure and midline fusion (Stumpo et al., 1995; Brouns et al., 2000). Midline fusion was normal in our GAP-43 (-/-) mice (Y. Shen and K. F. Meiri, unpublished results), as well as the guidance receptor mutants (Fazeli et al., 1997; Bergemann et al., 1998), indicating that callosal agenesis does not require fusion to be disrupted and suggesting that the two effects might be independent. In fact, the severity of the phenotype closely parallels the extent of protein distribution in growth cones. For instance, GAP-43, MARCKs, and p190rhoGAP, in which penetrance is $100 \%$, are all highly enriched throughout growth cones (Meiri et al., 1988; Wiederkehr et al., 1997; Brouns et al., 2001), whereas Mena and ankyrin $_{\mathrm{B}}$ in which penetrance is only $\sim 50 \%$, are limited to the tips of filopodia and sites of contact, respectively (Scotland et al., 1998; Lanier et al., 1999).

In GAP-43 (-/-), mice the Probst's bundles were located at the glial wedge, a bilateral structure thought to act as a source of deflective signals that direct midline axons toward the midline (Shu and Richards, 2001). Nonetheless, GAP-43 (-/-) axons responded normally to Slit-2, the proposed repulsive signal secreted by the glial wedge. Even so, glial abnormalities may also 

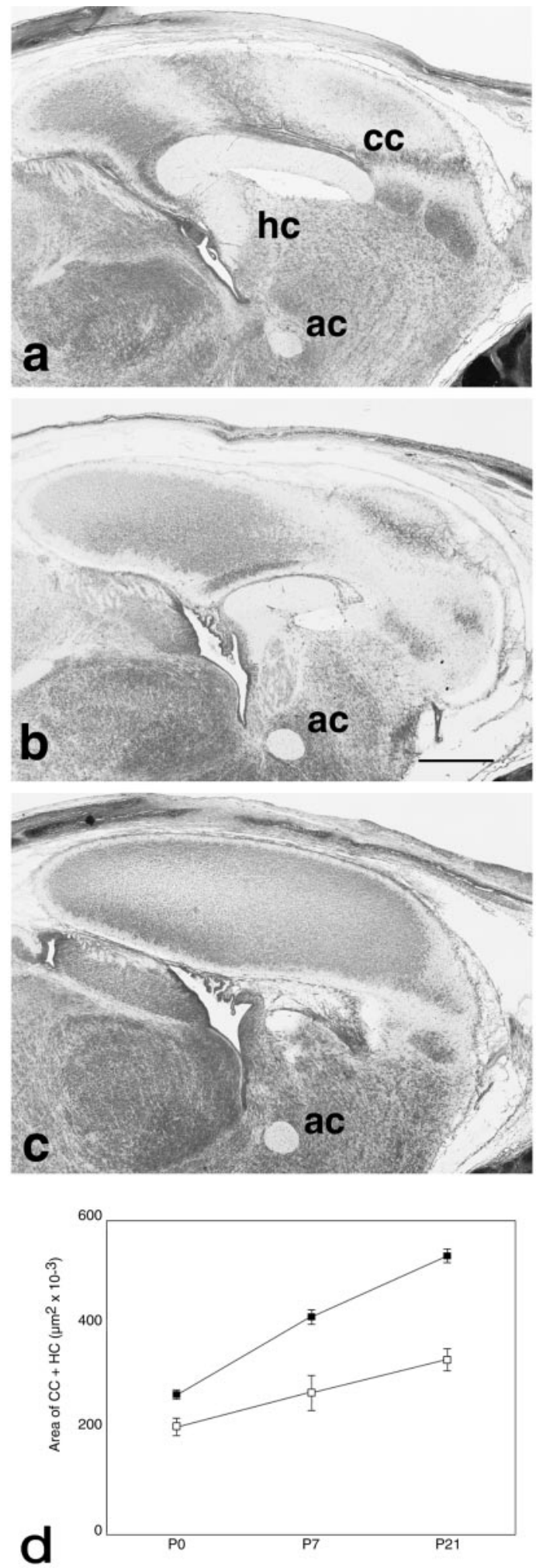

Figure 6. $a-c$, Nissl-stained parasagittal sections close to the midline of GAP-43 (+/-) forebrains at P0 showing corpus callosum ( $c c)$, hippocampal commissure $(h c)$, and anterior commissure $(a c)$. The severity of phenotypes in the $(+/-)$ ranges from reduced size of $\mathrm{CC}$ and $\mathrm{HC}(a, b)$ to complete absence of both commissures $(c)$. Note that the anterior commissure is normal in all cases. Scale bar, $250 \mu \mathrm{m}$. $d$, The area of the $\mathrm{CC}-\mathrm{HC}$ at midsagittal levels was measured at P0, P7, and P21 in GAP-43 $(+/+)(\square)$ and those GAP-43 (+/-) $(\square)$ mice with commissures. Results presented as mean \pm SEM; $n \geq 3$ in each case. There was a significant reduction in size of the $\mathrm{HC}$ and $\mathrm{CC}$ at both $\mathrm{P} 7$ and $\mathrm{P} 21(p<0.05)$.
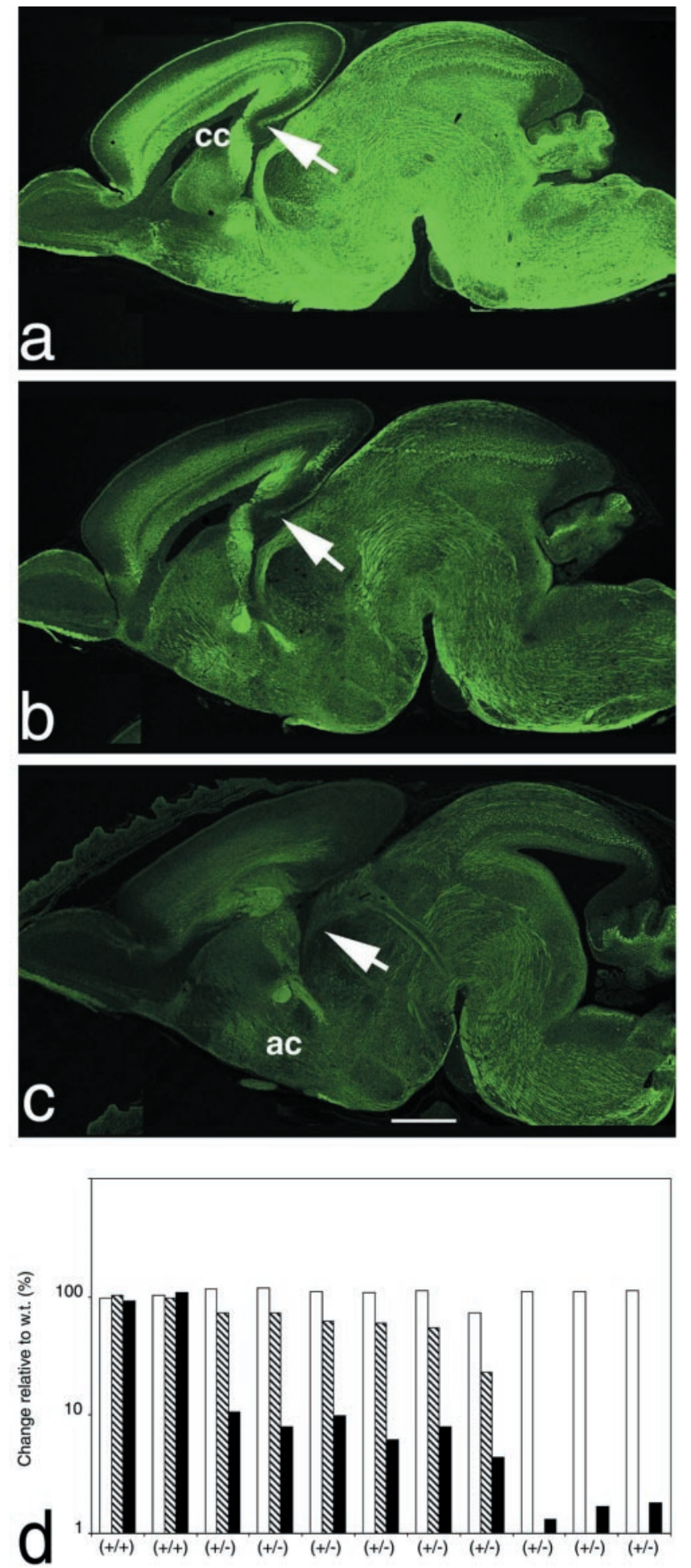

Figure 7. $a-c$, Parasaggital sections at P0, from GAP-43 $(+/+)(a)$ and $(+/-)(b, c)$ mice labeled with the anti-phospho-GAP-43-specific mAb 2G12, followed by FITC mice and arranged according to severity of callosal phenotype (CC). Arrows indicate position of the CC. There is less PKC phosphorylated in both cortex and CC in GAP-43 (+/-) compared with $(+/+)$. On the other hand, phosphorylation in the AC appears normal. Scale bar, 500 $\mu \mathrm{m}$. $d$, Reduction in callosal area of GAP-43 (+/-) mice correlates with the amount of phosphorylated GAP-43 in anterior cortex. White bars indicate area of $\mathrm{AC}$, hatched bars indicate area of $\mathrm{CC}$, and black bars indicate the amount of PKC-phosphorylated GAP-43 in anterior cortex quantitated from Western blots by ${ }^{125}$ I-labeled secondary antibody, followed by PhosphorImager analysis. Note that the quantitative results are presented on a log scale. 
contribute to the phenotype. GAP-43 is first upregulated in neuronal precursors that are at least bipotential (Sensenbrenner et al., 1997) and, when depleted, inhibits both neuronal and glial differentiation (Mani et al., 1999). In fact, preliminary evidence suggests that these glia may be immature (Shen and Meiri, unpublished results). In this regard, the differing relationships between commissural axons and their supporting glial pathways may also explain why the AC but not the CC is spared in GAP-43 $(+/-)$ mice. In the case of the $\mathrm{CC}$, axons are actively guided across the midline by a precise temporal coordination of midline fusion, glial wedge function, and sling formation (Shu and Richards, 2001). In contrast, in the case of the AC, axon guidance is a substantially more passive process because a defined glial channel is already in place (Pires-Neto et al., 1998).

IgSF members, notably L1CAM and neural cell adhesion molecule (NCAM), as well as basic FGF (bFGF), stimulate GAP-43 phosphorylation in growth cones (Meiri et al., 1998; Tejero-Diez et al., 2000). Moreover, elimination of GAP-43 blocked neurite outgrowth stimulated by either CAMs or bFGF, indicating its centrality in mediating the effects of IgSF-type CAMs, at least in vitro (Meiri et al., 1998). Interestingly, bFGF-mediated stimulation of GAP-43 phosphorylation also increased its association with the actin cytoskeleton (Tejero-Diez et al., 2000). Hence, the disruption in selective fasciculation suggests that one component of the GAP-43 phenotype may be failure to transduce CAMmediated signals. However, although several IgSF members, most notably TAG1 and L1, have been located in commissural axons (Fujimori et al., 2000) and functional mutations of L1 and its intracellular signal transduction pathway (which involves the FGF receptor 1) also lead to callosal agenesis in humans (Kamiguchi et al., 1998), failure of IgSF-mediated signaling alone seems unlikely to account for the GAP-43 phenotype: no callosal defects have been reported in mice deficient in all NCAM isoforms (Cremer et al., 1997), and callosal deficits in L1 mutant mice are manifest as reduced size rather than agenesis (Demyanenko et al., 1999). Thus, absent a significant combinatorial effect between IgSF members in the callosum, our results suggest that regulation of GAP-43 phosphorylation by yet another receptor-mediated mechanism may also be required for hemispheric communication across the $\mathrm{HC}$ and $\mathrm{CC}$.

GAP-43 is required for midline crossing only in the telencephalon. At the optic chiasm, retinal ganglion cells do cross the midline, although subsequent guidance is impaired (Kruger et al., 1998; Sretavan and Kruger, 1998). Likewise, axon crossing through the habenular, posterior, and ventral spinal commissures was normal (Shen and Meiri, unpublished results). Similarly, many neurons, especially in the periphery, are resistant to the absence of GAP-43 (Strittmatter et al., 1995). We do not yet understand why, nor why GAP-43 expression does not reach a functional threshold in the heterozygote cortex. Both results suggest the involvement of genetic modifier(s). It will be important to understand how a functional threshold of GAP-43 is achieved. Heterozygote deletions of the human 3q13.10-3q13.21 locus that encompasses the GAP-43 gene give rise to callosal agenesis, together with severe mental retardation (Jenkins et al., 1985; McMorrow et al., 1986; Okada et al., 1987; Genuardi et al., 1994; Mackie Ogilvie et al., 1998). Our results suggest that a mutation restricted to the GAP-43 gene itself will also cause predisposition to a dominantly transmitted abnormal CNS phenotype.

\section{REFERENCES}

Abbie AA (1940) The origin of the corpus callosum and the fate of structures related to it. J Comp Neurol 70:9-44.

Aigner L, Caroni P (1993) Depletion of 43-kD growth-associated protein in primary sensory neurons leads to diminished formation and spreading of growth cones. J Cell Biol 123:417-429.

Brouns MR, Matheson SF, Hu KQ, Delalle I, Caviness VS, Silver J, Bronson RT, Settleman J (2000) The adhesion signaling molecule p190rhoGAP is required for morphogenetic processes in neural development. Development 127:4891-4903.

Brouns MR, Matheson SF, Settleman J (2001) P190 RhoGAP is the principal src substrate in brain and regulates axon outgrowth, guidance and fasciculation. Nat Cell Biol 3:361-366.

Bulman-Fleming B, Wahlsten D (1991) The effects of intrauterine position on the degree of corpus callosum deficiency in two substrains of BALB/c mice. Dev Psychobiol 24:395-412.

Chen J, Chang S, Duncan SA, Okano HJ, Fishell G, Aderem A (1996) Disruption of the MacMARCKS gene prevents cranial neural tube closure and results in anencephaly. Proc Natl Acad Sci USA 93:6275-6279.

Cremer H, Chazal G, Goridis C, Represa A (1997) NCAM is essential for axonal growth and fasciculation in the hippocampus. Mol Cell Neurosci 8:323-335.

Demyanenko GP, Tsai AY, Maness PF (1999) Abnormalities in neuronal process extension, hippocampal development, and the ventricular system of L1 knockout mice. J Neurosci 19:4907-4920.

Dent EW, Meiri KF (1992) GAP-43 phosphorylation is dynamically regulated in individual growth cones. J Neurobiol 8:1037-1053.

Dent EW, Meiri KF (1998) Distribution of phosphorylated GAP-43 (neuromodulin) in growth cones directly reflects growth cone behavior. J Neurobiol 35:287-299.

Fazeli A, Dickinson SL, Hermiston ML, Tighe RV, Steen RG, Small CG, Stoeckli ET, Keino-Masu K, Masu M, Rayburn H, Simons J, Bronson RT, Gordon JI, Tessier-Lavigne M, Weinberg RA (1997) Phenotype of mice lacking functional Deleted in colorectal cancer (Dcc) gene. Nature 386:796-804.

Frey D, Laux T, Xu L, Schneider C, Caroni P (2000) Shared and unique roles of CAP23 and GAP43 in actin regulation, neurite outgrowth, and anatomical plasticity. J Cell Biol 149:1443-1454.

Fujimori KE, Takeuchi K, Yazaki T, Uyemura K, Nojyo Y, Tamamki N (2000) Expression of L1 and TAG-1 in the corticospinal, callosal, and hippocampal commissural neurons in the developing rat telencephalon as revealed by retrograde and in situ hybridization double labeling. J Comp Neurol 417:275-288.

Genuardi M, Calvieri F, Tozzi C, Coslovi R, Neri G (1994) A new case of interstitial deletion of chromosome 3q, del(3q)(q13.12q21.3), with agenesis of the corpus callosum. Clin Dysmorphol 3:292-296.

He Q, Dent EW, Meiri KF (1997) Modulation of actin filament behavior by GAP-43 (neruomodulin) is dependent on the phosphorylation status of serine 41, the protein kinase C site. J Neurosci 17:3515-3524.

Jenkins MB, Stang HJ, Davis E, Boyd L (1985) Deletion of proximal long arm in chromosome 3 in an infant with features of turner syndrome. Ann Genet 28:42-44.

Kamiguchi H, Hlavin ML, Yamasaki M, Lemmon V (1998) Adhesion molecules and inherited diseases of the human nervous system. Annu Rev Neurosci 21:97-125.

Kruger K, Tam AS, Lu C, Sretavan DW (1998) Retinal ganglion cell axon progression from the optic chiasm to initiate optic tract development requires cell autonomous function of GAP-43. J Neurosci 18:5692-5705.

Lanier LM, Gates MA, Witke W, Menzies AS, Wehman AM, Macklis JD, Kwiatkowski D, Soriano P, Gertler FB (1999) Mena is required for neurulation and commissure formation. Neuron 22:313-325.

Laux T, Fukami K, Thelen M, Golub G, Frey D, Caroni P (2000) GAP43, MARCKS, and CAP23 modulate PI $(4,5) \mathrm{P}(2)$ at plasmalemmal rafts, and regulate cell cortex actin dynamics through a common mechanism. J Cell Biol 149:1455-1472.

Livy D, Wahlsten D (1991) Tests of genetic allelism between four inbred mouse strains with absent corpus callosum. J Heredity 82:459-464.

Livy DJ, Schalomon PM, Roy M, Zacharias MC, Pimenta J, Lent R, Wahlsten D (1997) Increased axon number in the anterior commissure of mice lacking a corpus callosum. Exp Neurol 146:491-501.

Mackie Ogilvie C, Rooney SC, Hodgson SV, Berry AC (1998) Deletion of chromosome $3 \mathrm{q}$ proximal region gives rise to a variable phenotype. Clin Genet 53:220-222.

Magara F, Muller U, Li ZW, Lipp HP, Weissmann C, Stagljar M, Wolfer DP (1999) Genetic background changes the pattern of forebrain commissure defects in transgenic mice underexpressing the beta-amyloidprecursor protein. Proc Natl Acad Sci USA 96:4656-4661.

Maier DL, Mani S, Donovan SL, Soppet D, Tessarollo L, McCasland JS, Meiri KF (1999) Disrupted cortical map and absence of cortical barrels in growth-associated protein (GAP)-43 knockout mice. Proc Natl Acad Sci USA 96:9397-9402.

Mani S, Schaefer JS, Meiri KF (1999) Targeted disruption of GAP-43 in P19 embryonal carcinoma cells inhibits neuronal differentiation as well 
as acquisition of the mature neuronal phenotype. Brain Res 853:384-395.

McMorrow LE, Reid CS, Coleman J, Medeiros A, D'Andrea M, Santucci T, McCormack MK (1986) A new interstitial deletion of the long arm of chromosome 3. Am J Human Genet 39:366.

Meiri KF, Willard M, Johnson MI (1988) Distribution and phosphorylation of the growth-associated protein GAP-43 in regenerating sympathetic neurons in culture. J Neurosci 8:2571-2581.

Meiri KF, Saffell J, Walsh FS, Doherty P (1998) Neurite outgrowth stimulated by neural cell adhesion molecules requires growthassociated protein-43 (GAP-43) function and is associated with GAP-43 phosphorylation in growth cones. J Neurosci 18:10429-10536.

Mueller BK (1999) Growth cone guidance: first steps towards a deeper understanding. Annu Rev Neurosci 22:351-388.

Oestreicher AB, De Graan PN, Gispen WH, Verhaagen J, Schrama LH (1997) B-50, the growth associated protein-43: modulation of cell morphology and communication in the nervous system. Prog Neurobiol 53:627-686.

Okada N, Hasegawa T, Osawa M, Fukuyama Y (1987) A case of de novo interstitial deletion 3q. J Med Genet 24:305-308.

Ozaki HS, Wahlsten D (1992) Prenatal formation of the normal mouse corpus callosum: a quantitative study with carbocyanine dyes. J Comp Neurol 323:81-90.

Ozaki HS, Wahlsten D (1998) Timing and origin of the first cortical axons to project through the corpus callosum and the subsequent emergence of callosal projection cells in mouse. J Comp Neurol 400:197-206.

Philip N, Chabrol B, Lethel V (1998) Genetics of agenesis of the corpus callosum. Neurochirurgie 44:99-101.

Pires-Neto MA, Braga-De-Souza S, Lent R (1998) Molecular tunnels and boundaries for growing axons in the anterior commissure of hamster embryos. J Comp Neurol 399:176-188.

Rosner H, Vacun G (1999) 1,2-dioctanoyl-s,n-glycerol-induced activation of protein kinase $\mathrm{C}$ results in striking, but reversible growth cone shape changes and an accumulation of f-actin and serine 41phosphorylated GAP-43 in the axonal process. Eur J Cell Biol 78:698-706.

Scotland P, Zhou D, Benveniste H, Bennett V (1998) Nervous system defects of AnkyrinB $(-/-)$ mice suggest functional overlap between the cell adhesion molecule L1 and 440-kD AnkyrinB in premyelinated axons. J Cell Biol 143:1305-1315.

Sensenbrenner M, Lucas M, Deloulme JC (1997) Expression of two neuronal markers, growth-associated protein 43 and neuron-specific enolase, in rat glial cells. J Mol Med 75:653-663.

Shu T, Richards LJ (2001) Cortical axon guidance by the glial wedge during the development of the corpus callosum. J Neurosci 21:2749-2758.

Sretavan DW, Kruger K (1998) Randomized retinal ganglion cell axon routing at the optic chiasm of GAP-43-deficient mice: association with midline recrossing and lack of normal ipsilateral axon turning. J Neurosci 18:10502-10513.

Strittmatter SM, Fankhauser C, Huang PL, Mashimo H, Fishman MC (1995) Neuronal pathfinding is abnormal in mice lacking the neuronal growth cone protein GAP-43. Cell 80:445-452.

Stumpo DJ, Bock CB, Tuttle JS, Blackshear PJ (1995) MARCKS deficiency in mice leads to abnormal brain development and perinatal death. Proc Natl Acad Sci USA 92:944-948.

Tear G (1999) Neuronal guidance. A genetic perspective. Trends Genet 15:113-118.

Tejero-Diez P, Rodriguez-Sanchez M, Martin-Cofreces NB, Diez-Guerra FJ (2000) bFGF stimulates GAP-43 phosphorylation at ser41, modifies its intracellular localization in cultured hippocampal neurons. Mol Cell Neurosci 16:766-780.

Velut S, Destrieux C, Kakou M (1998) Morphologic anatomy of the corpus callosum. Neurochirurgie 44:17-30.

Wahlsten D, Schalomon PM, Crabbe JC, Dudek BC (1999) Behavioral effects of absent corpus callosum and the $5 \mathrm{HT} 1 \mathrm{~B}-/-$ knockout in strain 129 mice. Soc Neurosci Abstr 25:32.16.

Wiederkehr A, Staple J, Caroni P (1997) The motility-associated proteins GAP-43, MARCKS, and CAP-23 share unique targeting and surface activity-inducing properties. Exp Cell Res 236:103-116.

Wilkie AO (1994) The molecular basis of genetic dominance. J Med Genet 31:89-98.

Wolfer DP, Henehan-Beatty A, Stoeckli ET, Sonderegger P, Lipp HP (1994) Distribution of TAG-1/axonin-1 in fibre tracts and migratory streams of the developing mouse nervous system. J Comp Neurol 345:1-32. 